\title{
NUEVAS AMENAZAS PARA EL ECUADOR EN LA FRONTERA NORTE
}

\section{RESUMEN}

Mayo de IM. Franklin Celi Jimenez ${ }^{1}$

Para las entidades de seguridad del estado ecuatoriano es importante realizar un seguimiento permanente de las nuevas amenazas que intentan posesionarse en sectores vulnerables de la frontera norte; sin duda alguna este fenómeno ha tomado mayor relevancia como producto de la situación violenta que vive Colombia, pues el proceso de paz ha mantenido altos y bajos, evidenciando varios escenarios que involucran también a la seguridad de nuestro país.

En la frontera común colombo- ecuatoriana es evidente el impacto y contaminación derivado del problema colombiano, donde la presencia de grupos disidentes, traficantes de armas integrados con redes del narcotráfico y el crimen organizado, incrementan la violencia y generan inseguridad.

Por otro lado, es fundamental reconocer la ausencia del Estado en la frontera norte, principalmente en sectores más necesitados, donde la presencia de estructuras ilegales y violentas están influenciando en la sociedad, pues ya sea en forma voluntaria o bajo presión la sociedad común se ve envuelta en todo tipo de actividades ilícitas, ejemplo claro de esto es la cantidad de ciudadanos ecuatorianos detenidos en centro américa por vínculos con las redes del narcotráfico.

Palabras Clave: Nuevas Amenazas, frontera norte.

\begin{abstract}
For the security entities of the Ecuadorian state, it is important to constantly monitor the new threats that seek to take possession of vulnerable sectors of the northern border; Undoubtedly, this phenomenon has taken on greater relevance as a result of the violent situation in Colombia, since the peace process has kept ups and downs, showing several situations that also involve the security of our country.

On the Colombian-Ecuadorian common border, the impact and pollution derived from the Colombian problem is evident, where the presence of dissident groups, arms dealers integrated with drug trafficking networks and organized crime, increases violence and insecurity.

On the other hand, it is essential to recognize the absence of the State on the northern border, mainly in more necessary sectors, where the presence of illegal and violent structures are influencing society, since either the common society, voluntarily or under pressure which is involved in this type of activities.
\end{abstract}

Keywords: New threats, Northern Border

\footnotetext{
1 fjcj_20@yahoo.com

ACADEMIA DE GUERRA
} 


\section{Introducción}

Al momento para el Estado ecuatoriano, en especial para las Fuerzas Armadas se constituye en un aspecto de alto interés la seguridad en la frontera norte, esto debido a la misión constitucional y tareas asignadas a las unidades que al momento se emplean en este sector.

Para las organizaciones responsables por la seguridad del Estado, siempre se ha mantenido un seguimiento al problema interno de Colombia, debido a la influencia directa de este fenómeno en la seguridad de la población fronteriza y del Estado en general.

Para el Estado ecuatoriano es prioridad mantener niveles de seguridad adecuados en la frontera norte que permitan el normal desarrollo de las actividades en estos sectores; evidencia de la relevancia que se otorga a estos hechos son las continuas reuniones bilaterales en los niveles político estratégico y estratégico militar, donde se busca definir los mejores procedimientos encaminados a mejorar y mantener niveles de seguridad.

Ante la evidencia de los hechos y sustentados en la estadística que refleja el incremento de actividades ilegales en este sector, se genera una alerta en todas las estructuras del Estado, siendo necesario plantear estrategias que permitan combatir el problema y buscar soluciones.

Para toda la región el problema interno de Colombia ha tenido consecuencias, pero principalmente para nuestro país debido a la coyuntura geopolítica; es así que la frontera norte siempre se ha constituido en un sector con presencia de estructuras ilegales, pero en la actualidad como un evento colateral por la firma de la paz entre grupos irregulares de ese país y el estado, su influencia se ha incrementado, demostrando capacidad para ejecutar acciones violentas que atentan a la seguridad del Estado ecuatoriano.

Analizar las nuevas amenazas presentes en la frontera norte y como estas han mutado producto de la influencia del proceso de paz en Colombia, permitirá identificar las capacidades que han desarrollado y levantar escenarios basados en información procesada.

Con lo expuesto podemos plantear que, se está afectando la seguridad del Estado ecuatoriano en la frontera norte, por la presencia de nuevas amenazas derivadas del proceso de paz en Colombia.

\section{Amenazas prioritarias en el ámbito de la seguridad.}

Hoy en día las nuevas amenazas que afectan a la seguridad humana, han sido el punto principal de análisis en diversos debates a nivel internacional, como ocurrió en la Conferencia Especial sobre Seguridad "México 2003", ya que de una u otra manera dificultan el desarrollo de los países por la inseguridad e incertidumbre que ocasionan, razón por la cual es imperativo tener muy en cuenta que la mayoría de amenazas y riesgos en la actualidad tienen un carácter intermésticos y trasnacional.

En relación a este tema, la Junta Interamericana de Defensa menciona., "Además de las amenazas tradicionales, la seguridad de los Estados y del hemisferio, está siendo afectada por las «Nuevas amenazas» o las denominadas «Amenazas emergentes». Esta nuevas amenazas presentes en nuestras sociedades, son principalmente el «Terrorismo», «La Delincuencia organizada», Tráfico de drogas ilícitas», Tráfico ilícito de armas», »Ataques cibernéticos «Corrupción», «Desastres Naturales», «Deterioro del Medio ambiente» y «Lavado de activos».

Para nuestro país, las amenazas y riesgos han sido ya conceptualizadas a través del manual de Derecho en las Operaciones, "una amenaza existe cuando se juntan dos elementos: por un lado, la intención de atentar contra los intereses y objetivos de la nación y por otro la capacidad para hacerlo. La intención sin capacidad la capacidad sin intención no constituye una amenaza. Las amenazas son hechos o situaciones que ponen en riesgo o peligro la integridad física y moral de una persona, grupo social o país, o de los recursos, patrimonio, heredad histórica, etc., materializados en actos ilícitos". "Riesgo, son aquellos aspectos y características del medio social, del entorno físico y del sistema institucional, que aumentan la probabilidad de surgimiento u ocurrencia de una actividad ilícita, en el caso del territorio nacional, un delito o una contravención."

Con lo expuesto y considerando la situación geopolítica actual de nuestro país en relación con la región y el mundo, se mencionan las siguientes amenazas:

\section{Grupos irregulares armados (GIA).}

La desmovilización de las FARC, una de las guerrillas más antiguas de la región, llevada a cabo en el mes de noviembre del año 2016, tuvo la intención de poner fin a un conflicto de más de medio siglo que ha dejado aproximadamente 220.000 muertos, decenas de miles de desaparecidos y casi 7 millones de desplazados internos (Associated Press, 2017). Sin embargo, según se había previsto, hubo algunos frentes que decidieron no acogerse a lo pactado. Estos frentes no aceptaron desmovilizarse, es decir, ir a las zonas veredales, entregar sus armas e insertarse a la vida legal, según lo estipula el acuerdo. El gobierno colombiano señala a estos guerrilleros como disidentes y su decisión de seguir armados los pone en oposición al acuerdo (Casey, 2017).

A lo largo de la frontera común entre Colombia y Ecuador, existen varios de estos grupos armados, que por su condición de disidentes necesitan posesionarse 
de ciertos espacios territoriales para poder continuar con sus actividades ilícitas, las cuales atentan contra la seguridad y desarrollo del Estado.

Entre estos grupos es preciso considerar al Frente "Oliver Sinisterra", el cual ha sido identificado parte de su dispositivo en Tumaco, Departamento de Nariño (Colombia), frente a la provincia de Esmeraldas. Este grupo alcanzo relevancia cuando liderado por Walter Arizala Vernaza, alias "Guacho" dado de baja por fuerzas colombianas, se le atribuyeron varios atentados en nuestro país, así como el asesinato de tres periodistas de un medio de comunicación local ecuatoriano, de dos civiles ecuatorianos y de cuatro militares pertenecientes al Batallón de Infantería de Marina "San Lorenzo" (Redacción El Universo, 2018).

Las acciones ilegales que este grupo de disidentes ha llevado a cabo, le ha permitido al Comando Conjunto de las Fuerzas Armadas (CC.FF.AA), calificarlos como Grupo Irregular Armado, el mismo que se encuentra aliado a cárteles del narcotráfico, incrementando la sensibilidad del tema por los vínculos con el tráfico de armas, combustibles, precursores químicos, control de rutas terrestres, aéreas y marítimas, y englobando a esto el crimen organizado con todo lo que este involucra.

Una vez que las ex Fuerzas Armadas Revolucionarias de Colombia (FARC), decidieron ingresar a un proceso de paz con el gobierno colombiano, existió una resistencia de ciertos grupos e integrantes para no acogerse a este proceso, que decidieron retomar las actividades ilícitas, creándose nuevos grupos de disidentes denominados como Grupos Irregulares Armados (GIA), que en la actualidad (según fuentes colombianas) serían aproximadamente 2.600 hombres en armas y 1.700 miembros en las redes de apoyo, con injerencia en 17 departamentos, 114 municipios y 4060 veredas de Colombia.

En este contexto es relevante incorporar lo que la Secretaría nacional de Inteligencia (SENAIN), informo en febrero de 2018, manifestando la existencia de seis nuevos grupos irregulares armados de Colombia que operan en la frontera con Ecuador. De acuerdo con la información presentada estas células estarían operando en el departamento Nariño, que limita con parte de las provincias de Esmeraldas, Carchi y Sucumbíos.

La SENAIN en ese momento menciona las siguientes bandas insurgentes:

- Clan del Golfo

- Frente Oliver Sinisterra

- Guerrillas Unidas del Pacífico

- Resistencia Campesina

- Gente de Orden y

- La Empresa
La división al interior de las FARC, por un lado la postura política de Rodrigo Londoño (a) "Timochenco", de mantener el proceso de reincorporación y por otro el regreso a la lucha armada por parte de (a) "Iván Márquez", ha provocado un distanciamiento entre los principales cabecillas de las ex FARC, donde la reagrupación de las ex FARC enfrenta varios obstáculos, siendo el principal que los GIA tienen intereses económicos más que ideológicos, disponen de una estructura estable y pretenden el dominio de los corredores de movilidad, determinando que la idea de (a) "Iván Márquez" de reagrupar a las ex FARC, es poco probable. Además, la existencia de economías ilegales, el crecimiento de las disidencias de las ex FARC y la autonomía que mantienen estos grupos, es una muestra de la ausencia de garantías de seguridad para la consolidación integral del proceso de paz, razón por la cual el Estado Colombiano, deberá crear condiciones de seguridad para brindar un escenario favorable al proceso de paz.

La presión militar que ejerce la FF.PP.CC y los continuos enfrentamientos que mantienen los GIA en los departamento de NARIÑO y PUTUMAYO (COLOMBIA), por el control de territorio y corredores de movilidad para el narcotráfico, podrían provocar el desplazamiento de ciudadanos colombianos y la infiltración de integrantes de las estructuras armadas hacia territorio ecuatoriano con la finalidad de ocupar refugios temporales que les permita brindar seguridad a sus cabecillas, buscar apoyo de ciudadanos ecuatorianos para ampliar sus redes de colaboradores y mantener el flujo logístico necesario para sus actividades ilegales, principalmente en las poblaciones de ESMERALDAS, CARCHI y SUCUMBÍOS.

El ELN a finales del año 2019 emitieron un comunicado donde señalan su intención de retornar al proceso de paz, estos acontecimiento se verán reflejados a mediano plazo, siempre que exista el comprometimiento de las dos partes; tomando en cuenta que ante la capacidad delictiva que tiene este grupo, continuará con las actividades ilícitas conexas al narcotráfico, utilizando los corredores de movilidad terrestres y fluviales existentes en la línea de frontera colombo-ecuatoriana, para el abastecimiento logístico e insumos químicos, incrementando la inseguridad en los habitantes de las provincias ESMERALDAS y CARCHI.

\section{Narcotráfico}

Para este tema se ha tomado como referencia lo que menciona "Insight Crime", donde expone que nuestro país se ha convertido en una zona geográfica de alta importancia estratégica para las redes del narcotráfico por:

- Posicionamiento entre grandes productores de droga

- País dolarizado

- Débil situación jurídica

- Carteles de la droga con perfil bajo 
Sin embargo, es una realidad que nuestro país se ha convertido en una ruta principal para la salida de la droga hacia el exterior.

Se puede establecer que gran parte de la producción de cocaína en Colombia llega actualmente a Ecuador, y sale de los puertos, las costas y los aeropuertos del país, hacia destinos como Estados Unidos, Europa e incluso Asia y Oceanía.

Es evidente el poder e influencia que sostiene este sistema ilegal, pudiendo afirmar que existe un complejo y fluido submundo conformado por grupos especializados y coordinados, por poderosas organizaciones transnacionales de narcotráfico y protegidos por redes de corrupción que penetran profundamente en el Estado.
Es importante considerar cuantitativamente eventos relacionados con este tema en el período del 18DIC-019 al 17-ENE-020:

- GUAYAS, LOS RÍOS e IMBABURA son las provincias con mayor cantidad de cocaína decomisada.

- LOJA y ESMERALDAS son las provincias con mayor cantidad de marihuana decomisada. Destacándose el empleo de la modalidad de contaminación de contenedor y caletas.

- Vinculación de tres ciudadanos de nacionalidad ecuatoriana a nivel internacional.

- La concentración de carga por decomiso de cocaína para el 2019 y lo que va del 2020 se registra en la región costa.

\section{Tráfico de drogas y sus rutas en Ecuador}

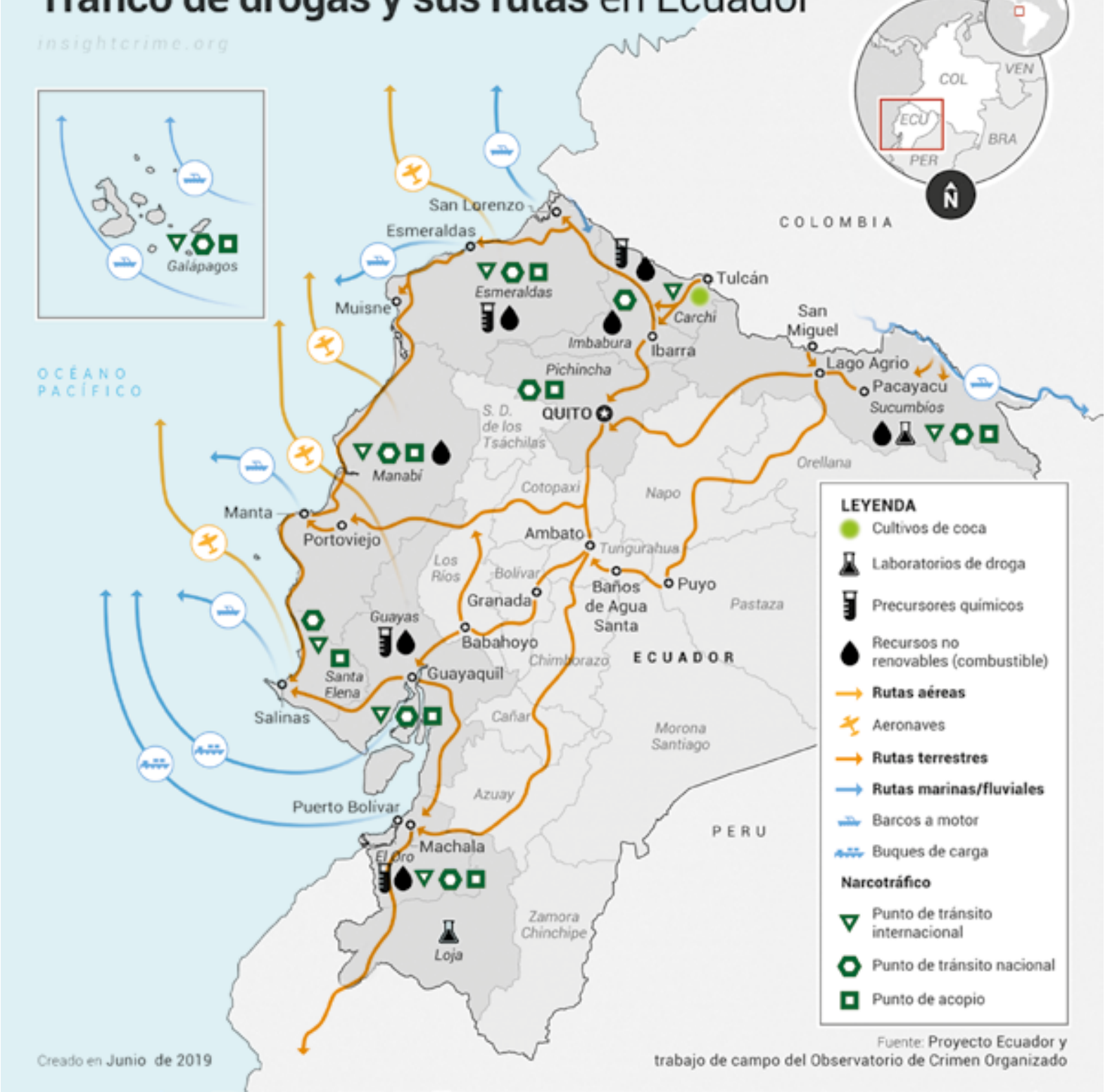

Figura 1. Datos estadísticos

(Fuente: Insight Crime) 
- Se destaca la provincia del GUAYAS, debido a que mantiene características exclusivas (puertos internacionales, aeropuerto internacional, concentración de población), siendo importante indicar que la entrada en funcionamiento del puerto de aguas profundas en POSORJA, permitirá que esta provincia continúe encabezando los ranking de decomisos de SCSF para el 2020.

\section{Crimen transnacional organizado.}

Son agrupaciones al margen de la ley que encaminan sus acciones para fines particulares, se caracterizan por no atentar directamente contra la seguridad del estado, sin embargo, si lo hacen en contra del patrimonio y la moral de la población civil; sus fines son de tipo económico, no tienen ideología y en algunos casos poseen una estructura donde los cabecillas son los que infunden temor y respeto entre sus integrantes; dentro de este se consideran los siguientes: el tráfico de armas, municiones y explosivos, el narcotráfico, el tráfico ilícito de inmigrantes, el contrabando de mercancías, el tráfico de personas (COIMC, 2019, pág. 5).

En nuestro país esta amenaza, ha incrementado los índices de inseguridad e incertidumbre, tal es así que, en los últimos años producto de la permeabilidad de las fronteras se ha generado un alto flujo migratorio de ciudadanos extranjeros, los cuales ingresaron al país sin un pasado judicial, causando problemas de seguridad intermésticos, que afectan a la seguridad y defensa, así tenemos: secuestro, sicariato, extorsión, tráfico de drogas, tráfico de seres humanos, tráfico de órganos, pornografía infantil, trata de blancas y otros males que han afectado a la sociedad.

\section{Minería ilegal}

La actividad extractiva ilegal en el Ecuador es un problema que ha venido incrementándose paulatinamente el último siglo, no solamente por la problemática social, si no por el impacto ambiental que conlleva dicha actividad carente de tecnología o un plan de gestión de residuos, obviando de todo aspecto la seguridad de los trabajadores que se benefician de esta actividad y al no contar con planes para su manejo, genera diferentes afectaciones al medio ambiente como el vertimiento de residuos contaminantes, afectaciones a los servicios ambientales por remoción del suelo y destrucción de áreas legalmente protegidas.

La minería informal, se estaría desarrollando en su mayoría como una minería artesanal informal, en los sectores donde se encuentran reservas de minerales en pequeñas, medianas o grandes cantidades, los trabajados lo realizan con familiares o de sociedades de hecho, auxiliados por maquinarias y herramientas mecánicas; las inversiones económicas son nacionales de ahorros propios o contribuciones de socios para adquirir maquinarias básicas y cubrir costos operativos (mano de obra, energía, insumos).

Pese a los controles que realizan los organismos responsables, con el propósito de suspender los trabajos de minería informal que no cuentan con los permisos respectivos, estas actividades se han mantenido, conllevando a mantener delitos conexos (tráfico de combustibles y explosivos), aprovechando la situación geográfica del terreno, ubicándose en lugares aledaños a concesiones mineras, lugares alejados de centros poblados, empleando maquinaria liviana, pesada y accesorios, mismos son operados por ciudadanos nacionales o extranjeros (colombianos y peruanos), causando la destrucción al ambiente, contaminación de fuentes de agua y deforestación de bosques, aprovechando la poca presencia de instituciones del Estado.

Las actividades de minería ilegal, en la provincia de ESMERALDAS, se evidencia como modus operandi el empleo de maquinaria tipo excavadoras, dragas y la utilización de químicos (mercurio) para la extracción y procesamiento del mineral (oro), en lo que respecta a la minería en EL CIELITO, la falta de control y acciones permanentes posterior al desalojo minero ocurrido a finales del año 2017, ha generado que este sector se convierta nuevamente en un objetivo para la extracción ilícita de material aurífero, en la provincia de SUCUMBÍOS se evidencia minería a cielo abierto en menor escala en el sector de CASCALES.

\section{DECOMISO DE MAQUINARIA FRONTERA NORTE AÑO 2018}

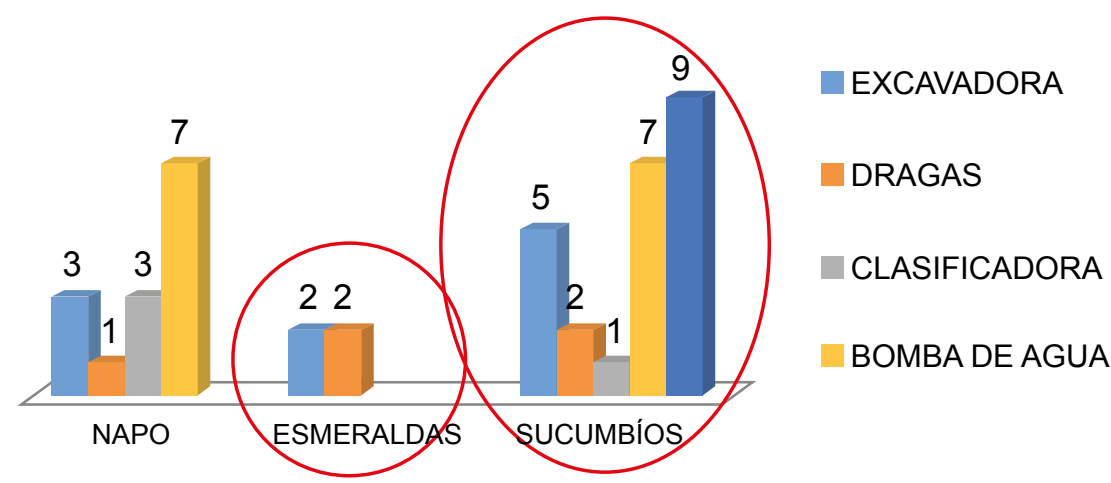

Figura 2. Datos estadísticos: Explotación ilegal de los recursos naturales / minería ilegal. (Fuente: COIMC) 


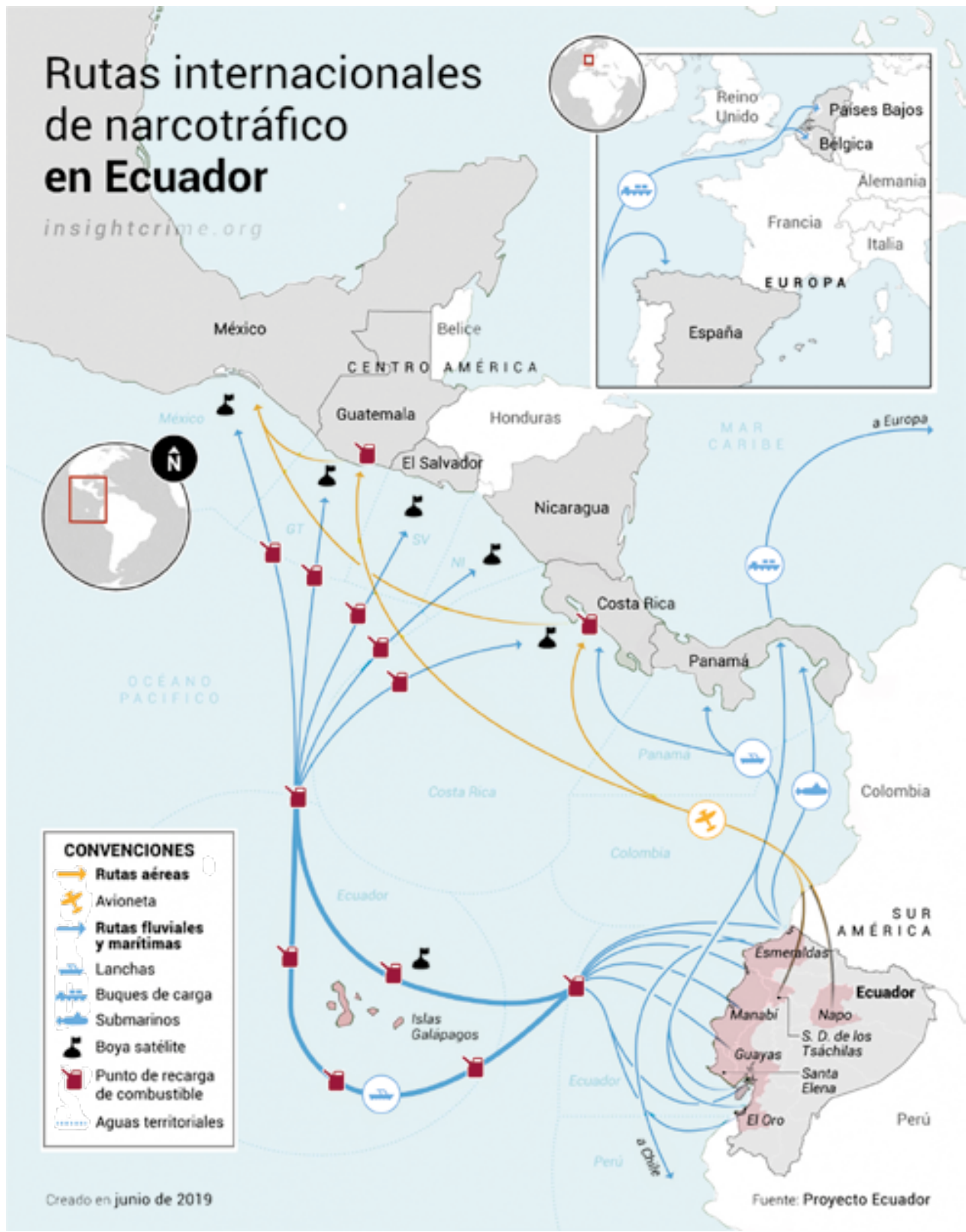

Figura 3. Mapa: Insight Crime.

(Fuente: Proyecto Ecuador)

\section{Violación del espacio aéreo}

Dentro de este aspecto es necesario considerar lo que establece el Manual de Derecho en las Operaciones:

"La Agenda Política de la Defensa y la Directiva de Defensa Militar, establecen, dentro del empleo de las Fuerzas Armadas, la ejecución de Operaciones Militares de Vigilancia y Control de los espacios del territorio nacional.

A la Fuerza Aérea le corresponde el espacio aéreo, que comprende operaciones de soberanía energética, seguridad hidrocarburífera, vigilancia y reconocimiento en la frontera norte e interceptación de aeronaves ilícitas en cumplimiento del mandato constitucional de apoyo a la acción del Estado".
Áreas Prohibidas (SEP).- Espacio aéreo de dimensiones definidas sobre el territorio o las aguas jurisdiccionales del Estado, dentro de los cuales está prohibido el vuelo de aeronaves sin autorización específica de la autoridad aérea correspondiente.

Áreas Restringida (SER).- Espacio aéreo de dimensiones definidas sobre el territorio o las aguas jurisdiccionales del Estado, dentro de los cuales está restringido el vuelo, de las aeronaves de acuerdo con determinadas condiciones específicas, operativas, técnicas o meteorológicas.

Respecto a la Interceptación de Aeronaves Ilícitas, que constituye una circunstancia particular de la Fuerza Aérea, se deberá cumplir lo que establece la norma- 
tiva Internacional de la Organización de Aviación Civil Internacional (OACI), contenida en el Convenio sobre Aviación Civil Internacional”.

Con lo expuesto, es evidente que existe un marco legal donde se ampara el accionar de los órganos responsables de proporcionar la seguridad en el espacio aéreo, entonces es fundamental para el estado dotar de capacidades operativas a la Fuerza aérea para que cumplan son su misión.

En la actualidad es claro una vulnerabilidad para el estado ecuatoriano, misma que se evidencia en los datos estadísticos que exponen la violación del espacio aéreo por parte aeronaves pertenecientes a carteles del narcotráfico.

Las estadísticas evidencian enviar cargamentos desde las costas continúa siendo el principal método para traficar cocaína con destino a Estados Unidos.

Con estos datos se afirma que nuestro país es usado como puente aéreo, hecho que se ha incrementado, como resultado, según las autoridades, de la creciente presión sobre las rutas marítimas.

Se identifica que los traficantes utilizan principalmente avionetas Cessna, las cuales son modificadas para que puedan transportar una mayor cantidad de drogas y combustible, y que incluso pueden reabastecerse en el aire. Estas avionetas pueden transportar entre 400 y 700 kilos, y tardan alrededor de seis horas para llegar a Costa Rica o Guatemala, donde descargan su contenido, o bien repostan y continúan hacia México.

Con esto se analiza que estas estructuras están en capacidad de mantener y operar por rutas aéreas ilegales ocupando nuestro espacio aéreo, aprovechando las limitaciones que realmente son evidentes, pues hasta el momento no existen datos donde refleje la interdicción aérea.

\section{Tráfico de armas, municiones y explosivos.}

El tráfico de armas, munición y explosivos bajo el dominio de la ilegalidad es un fenómeno complejo, por lo tanto, se debe pensar que el tráfico de armas es un vínculo adicional entre el terrorismo y la delincuencia organizada que explica la capacidad de grupos fuera de la ley para cometer actos ilícitos. En el Ecuador "se somete al control del Ministerio de Defensa Nacional a través del Comando Conjunto de las Fuerzas Armadas la importación, exportación, internamiento, almacenamiento, comercio interior y fabricación de armas de fuego, municiones, fuegos de artificio, pólvora o toda clase de explosivos, así como también las materias primas para fabricación de explosivos; los medios de inflamación tales como: guías para minas, fulminantes y detonadores; productos químicos, elementos de uso en la guerra química o adaptables a ella" .
Este tráfico de armas afecta a nuestro país en razón de que incrementa los niveles de inseguridad generando violencia, incertidumbre y temor en la población. El Gobierno Nacional, con el fin de reducir la cantidad de armas en el territorio ecuatoriano, a través de las entidades correspondientes, estableció el Acuerdo Ministerial 749 del 29-ABR-011, para prohibir el importe de armas a escala nacional y, desde el 03-FEB-012, se impidió la fabricación de armas artesanales.

Muchos de estos artesanos, fueron provistos de otras fuentes de empleo como fabricación de bancas escolares, camas; empleos que fueron esporádicos, por lo que varios migraron de los sitios donde se producían las armas, cerrando sus talleres.

Este armamento comúnmente dirigido a las empresas de seguridad, a la caza, una gran cantidad termina en manos de la delincuencia, debido al precio y a la comercialización no controlada. Ante esta situación las autoridades han tomado medidas drásticas a fin de evitar la producción de armas de fabricación artesanal, a pesar del esfuerzo que ha venido realizando el Gobierno no ha sido posible detener la producción, al contrario se ha diversificado y disipado, tornando difícil su localización.

Se ha identificado armas artesanales en manos de delincuencia común, manipuladas por guardias de seguridad "improvisados" en camaroneras, bananeras, minería ilegal, y para actividades de caza principalmente en las provincias amazónicas.

El tráfico de armas, hacia lado Colombiano en el año 2016 fue decrecido notablemente, debido principalmente al proceso de paz llevado a cabo por parte del Gobierno Colombiano, con las FARC, en donde se planteó como mecanismo para tal efecto el cese bilateral de fuego, ante lo cual los mandos de este grupo irregular concretaron simultáneamente frenar la adquisición de armamento.

\section{Migración.}

Por migración se entiende al: "Movimiento que realizan las personal de una población y que implica un cambio de localidad en su residencia habitual en un intervalo de tiempo determinado, cruzando fronteras o límites territoriales de una región geográfica. En esencia, en la inmigración intervienen dos áreas geográficas, aquella donde se inicia el desplazamiento (origen), y aquella donde finaliza el movimiento (destino). Dentro de las causas que generan estos movimientos poblacionales se resalta la situación económica

En nuestro país la migración ha generado falta de empleo, mano de obra barata, delincuencia común, incidentes xenófobos e inversión por parte del Estado Ecuatoriano ya que adquieren los mismos derechos que los ecuatorianos. 
Desde el inicio del 2018, se aprecia una tendencia creciente del flujo de ciudadanos venezolanos al país, con picos en los meses de octubre y diciembre y, picos en septiembre y noviembre. A partir de diciembre y lo que va del año 2019 se aprecia un decremento de flujo migratorio de venezolanos, existiendo un saldo migratorio de 154379 venezolanos a DIC-018. Los primeros migrantes tuvieron la oportunidad de conseguir trabajos formales, mientras que las siguientes olas de migración, tuvieron que acogerse al trabajo informal $\mathrm{y}$, en la actualidad la mayoría realiza tránsito hasta alcanzar otros países al sur del continente.

\section{Delitos en los espacios acuáticos}

Otro de los riesgos que se ha ido incrementando en los últimos años en el Ecuador lo constituyen los delitos perpetrados en el mar como lo son, entre los más recurrentes, el tráfico de combustibles, drogas y el robo de motores. El Ecuador es un Estado Marítimo por su posición geográfica equinoccial, su inmenso espacio marítimo jurisdiccional y su conexión directa a la cuenca Asia - Pacífico, tiene una riqueza marítima inexplorada y no cuantificada aún, con un potencial de recursos vivos y no vivos, cuyo cuidado y protección recae en el Estado ecuatoriano y en sus instituciones, siendo importante disponer de una Armada con la capacidad de proteger sus intereses marítimos, incluso más allá de sus espacios acuáticos jurisdiccionales.

\section{Conflictividad social}

El "TRIÁNGULO DE CUEMBÍ"; con una extensión de 104.238 hectáreas. Es importante indicar que las medidas de protesta efectuadas el 16-NOV-018, en primera instancia estuvieron enfocadas en la reforma de los Art. 2 y Art. 3 del mencionado Acuerdo, mismos indican que "El Ministerio de Ambiente tomará las medidas que sean pertinentes para garantizar que en el bosque no se autorice el otorgamiento de licencias de aprovechamiento forestal, ni la adjudicación de tierras a posesionarios asentados en el área, por tratarse de zona de Seguridad Nacional", al respecto no se ha llegado a ninguna resolución, lo que podría ser una motivación para iniciar nuevas medidas de protesta en lo posterior.

Entre los actores existen personas interesadas en habilitar rutas y medios para el transporte de precursores químicos y sustancias sujetas a fiscalización, a fin de obtener la activación de actividades ilícitas, en vista que frente a este sector, del lado colombiano, operaba el Frente 48 de las FARC, y actualmente se localizan los disidentes del Frente 48 con alias "SINALOA".

\section{Corrupción.}

La corrupción viene definida como soborno, coima o peculado es la acción y efecto de corromper, es sinónimo de abuso, desorden cohecho, seducción y depravación, perversión y desmoralización. Según el diccionario Razonado de Legislación y Jurisprudencia establece que la Corrupción es el crimen de que se hacen culpables los que estando revestidos de alguna autoridad pública; como igualmente el crimen que cometen los que tratan de corromperlos, de suerte que la corrupción puede considerarse como activa y como pasiva; activa de parte de los corruptores y pasiva de parte de los corrompidos.

En el fondo la corrupción puede convertirse en un problema cultural, el marco formativo y conductual predominante en nuestras sociedades, en una más y en otras menos es el individualismo, el consumismo, la carencia de valores, el afán por el poder, la codicia un exitismo económico reflejado en un tanto tienes tanto vale y el débil compromiso con lo público y con el bien común llegando así a la frustrante situación actual. La corrupción ha trastocado los valores de la ciudadanía y juventud ecuatoriana confundiendo lo que es correcto con lo incorrecto.

Los tipos de corrupción tenemos: la ineficiencia del sistema judicial u obstrucción de la justicia, nepotismo, colusión, uso ilegal de información confidencial, enriquecimiento oculto o ilícito, abuso de funciones, tráfico de influencias, peculado o desvió de recursos, el soborno y la conspiración para cometer actos de corrupción.

En nuestro país la constante es la denuncia de problemas graves frente al fenómeno de la corrupción, la impunidad permanente, la politización extrema, la tolerancia y la amoralidad ciudadana, el atraso legislativo, la burocracia y también corrupción en los organismos de control y juzgamiento, la desconfianza ciudadana en las instituciones del país en un recuadro dramático lo que demuestra lo complejo de la situación. Es así que la corrupción en nuestro país dejo de ser coyuntural para ser estructural.

\subsection{Marco legal}

La seguridad integral, de acuerdo a la Ley de Seguridad Pública y del Estado, tiene dos grandes dimensiones: la seguridad de los habitantes garantizada a través de la seguridad ciudadana; y la seguridad del Estado en sus dimensiones territorial e institucional (Plan Nacional de Seguridad Integral, 2014, pág. 20). De allí que conceptualmente, la seguridad integral tiene por finalidad garantizar y proteger los derechos humanos y las libertades de los ecuatorianos, la gobernabilidad, la aplicación de la justicia, el ejercicio de la democracia, la reducción de vulnerabilidades, la prevención, protección, respuesta y remediación ante riesgos y amenazas, para lo cual se requiere la participación activa, coordinada, cooperativa y complementaria de las diferentes instituciones o entidades del Estado. 
Derivada de la Constitución del 2008, la Ley de Seguridad Pública y del Estado en su Art. 5 menciona al "Sistema de Seguridad Pública y del Estado" cuya finalidad es coadyuvar al bienestar colectivo, al desarrollo integral, al ejercicio pleno de los derechos humanos y de los derechos y garantías constitucionales. Una de las entidades integrantes de este sistema son las FF.AA, las cuales forman parte de los organismos ejecutores del sector defensa (Ley de Seguridad Pública y del Estado, 2014, pág. 3).

De la Ley de Seguridad Pública y del Estado se deriva el Plan Nacional de Seguridad Integral y de este, entre otras, se deriva la Agenda Política de la Defensa, en la cual se contemplan cuatro misiones para las FF.AA (Agenda Política de la Defensa, 2014, pág. 38). Una de las misiones indica: Participar en la seguridad integral, por lo tanto, es propicio reflexionar que más allá de la misión principal de la institución militar que es la defensa de la soberanía e integridad territorial, las FF.AA deben adaptarse a las nuevas amenazas y riesgos que en los últimos tiempos han reconfigurado los escenarios, tal es el caso de los grupos irregulares armados, las organizaciones de narcotráfico y sus delitos conexos, las organizaciones criminales transnacionales, los ataques cibernéticos, el tráfico de armas, municiones y explosivos; la delincuencia común y organizada, la migración regular, la explotación ilegal de recursos naturales, los desastres naturales y antrópicos, el contrabando, la inequidad social, entre otros (Ministerio de Defensa Nacional, 2018, págs. 11-12), que demandan el empleo de las FF.AA en "misiones de complementariedad" en apoyo a la seguridad integral.

Consecuente con el criterio político del Gobierno Nacional y la Asamblea Nacional, en el mes de junio del 2014 fue modificado el Art. 35 de la Ley de Seguridad Pública y del Estado, agregando al Art 11 la facultad de las FF.AA para que puedan apoyar de forma complementaria a las operaciones que en materia de mantenimiento y control del orden público y la seguridad ciudadana competen a la Policía Nacional. Para tal efecto, los Ministros responsables de la Defensa Nacional y del Interior deben coordinar la oportunidad y el nivel de intervención. De esta manera se cambió el Art. 35 de la ley referente a la complementariedad de acciones de las FF.AA y Policía Nacional, para lo cual se requería declarar el estado de excepción por parte del Presidente de la República a fin de disponer el empleo de las FF.AA. Actualmente se considera que las FF.AA pueden actuar de manera complementaria con la Policía Nacional en todos los aspectos relacionados al mantenimiento y control del orden público y la seguridad ciudadana, sin la necesidad de que se haya decretado el estado de excepción.

Con la finalidad de establecer los niveles de coordinación para la implementación y ejecución de ope- raciones de complementariedad entre FF.AA y Policía Nacional como lo establece el Art. 11 de la Ley de Seguridad Pública y del Estado, se creó el Centro de Coordinación Estratégico Integrado. Para que se lleven a cabo estas actividades se deben realizar coordinaciones en el nivel político (entre Ministro de Defensa y Ministro del Interior) y en el nivel estratégico integral (entre el Jefe del CC.FF.AA y el Comandante General de la Policía Nacional), lo cual permitirá que se coordinen efectivamente los protocolos de apoyo a la complementariedad de las FF.AA a la Policía Nacional (Ministerio de Defensa Nacional, 2015).

Además del apoyo a la Policía Nacional, las FF.AA también participan apoyando a otras instituciones con las cuales se mantienen convenios de cooperación interinstitucional, acuerdos ministeriales y protocolos de intervención que ha llevado a cabo el Ministerio de Defensa Nacional con otras instituciones públicas, lo que permitirá determinar el ámbito de aplicación, vigencia, normas de comportamiento, la legalidad y legitimidad en el cumplimiento de las operaciones militares en el ámbito interno. Entre las entidades del estado consideradas se enuncian las siguientes: SENAE, SGR, SENESCYT, SRI, ARCOM, ARCH, MAGAP, MAE, MSP, CNE, ECORAE (Cárdenas, Allauca, \& Jiménez, 2017).

Al derogarse la enmienda relacionada a la complementariedad a la seguridad integral, la misión fundamental de FF.AA sería la que originalmente constaba en la Constitución 2008, la cual define la verdadera razón de ser y de existir de la institución militar, sin embargo es necesario considerar que el apoyo de las FF.AA a la seguridad interna del Estado siempre ha sido realizado, ya sea bajo decreto de estado de excepción o por orden transmitida a través de una medida cautelar como la emitida en el año 2010 por el Juzgado Vigésimo Segundo de Garantías Penales de Pichincha. Entre algunas de las posibles acciones ante la derogatoria de la enmienda, se podrían reconsiderar los convenios con varias entidades del Estado, lo cual obliga a la reestructuración de las operaciones en el ámbito interno que en la actualidad considera el Comando Conjunto de las FF.AA. De todas maneras, es necesario tomar en cuenta que las entidades del Estado requieren del apoyo permanente de las FF.AA, por lo cual los convenios con certeza van a mantener su vigencia y los protocolos se van a cumplir a pesar de que la enmienda se haya derogado, considerando que la Constitución en su Art. 3 numeral 8 garantiza la seguridad integral y en su Art. 226 dispone la coordinación de acciones de las instituciones del Estado para garantizar los derechos que la Carta Magna reconoce, entre los cuales está el derecho a la integridad física y a una vida libre de violencia. 


\section{Conclusiones}

La crisis de la frontera nor-occidental ha incidido para que el Estado inicie el establecimiento de una política pública de defensa y seguridad en dicha frontera, buscando el desarrollo productivo de la zona fronteriza, el mejoramiento del nivel de vida de su población y la lucha frontal, sin desatinos ideológicos, contra la guerrilla colombiana, el terrorismo y el narcotráfico, exigiendo del Estado colombiano una participación efectiva en esa lucha.

A causa del problema en la frontera norte, el estado ecuatoriano va a garantizar la soberanía, protección y desarrollo de la población siempre respetando los DDHH y libertades estipuladas en la constitución del Ecuador.

Los escenarios que se van presentando en la actualidad exigen de las FF.AA una preparación, entrenamiento y equipamiento acorde a las nuevas exigencias de las nuevas amenazas como los G.I.A, el narcotráfico, la delincuencia común y el crimen organizado, pero todo esto solamente se podrá combatir con unas FF.AA profesionales y totalmente preparadas tecnológicamente acción que solo se conseguirá con las políticas de estado que el gobierno de turno las emita, manteniendo relaciones con potencias que proporcionen su apoyo tecnológico y de capacitación y entrenamiento para sus miembros.

La tarea de FF. AA trabaja enfocada en un solo objetivo, la seguridad interna y externa del Estado Ecuatoriano, el apoyo a las instituciones del estado para garantizar una vida de paz y tranquilidad de todos los ciudadanos ecuatorianos.

Mientras sigan en vigencia las reformas a la Ley de Seguridad Pública y del Estado, principalmente en su Art. 11 el rol asignado a las FF.AA implica la adaptación a los nuevos escenarios derivados de los riesgos y amenazas, lo cual exige y demanda otros ámbitos de preparación y entrenamiento, para garantizar su capacidad operativa y administrativa, que permita cumplir con los lineamientos políticos y los objetivos nacionales del Estado direccionados a la seguridad integral.

\section{REFERENCIAS}

[1] Andrade, R. V. (24 de noviembre de 2005). Derecho Ecuador.com. Obtenido de Derecho

[2] Ecuador.com: https://www. derechoecuador.com/lavado-de-dinero

[3] Asamblea Nacional del Ecuador. (2008). La Constitución. Montecristi: Asamblea Nacional.

[4] Asamblea Nacional del Ecuador. (2008). Constititución de la República del Ecuador. Montecristi: Publicación Oficial de la Asamblea Nacional.

[5] COIMC. (15 de enero de 2019). Amenazas y riesgos a la defensa y seguridad del estado. Amenazas y riesgos a la defensa y seguridad del estado. Sangolquí, Pichincha, Ecuador: COIMC.

[6] Comando de Educación y Doctrina Militar Terrestre. (2015). Manual de operaciones en el Ámbito Interno (OAI). Quito: AGE
[7] Departamento de Seguridad Nacional. (31 de enero de 2019). Riesgos y Amenazas para la Seguridad Nacional/DSN . Obtenido de Riesgos y Amenazas para la Seguridad Nacional/DSN : http://www.dsn.gob. es/es/sistema-seguridad-nacional/ qu $\%$ C3\%A9-es-seguridad-nacional/ riesgos-amenazas-para-seguridadnacional

[8] Francisco, U. (2015). Ciberataques la mayor amenaza actual. Instituto Español de Estudios Estrategicos., 3-4.

[9] Fundación para la prevención de riesgos laborales. (2015). Portal de los riesgos laborales. Obtenido de Portal de los riesgos laborales: www. http:riesgoslaborales.feteugt-sma.es

[10] Meteorología en Red. (16 de abril de 2018). Obtenido de Fenómenos Naturales: https://www. meteorologiaenred.com/inundaciones. html
[11] Ministerio de Defensa Nacional . (2018). Politicas de la Defensa, Seguridad y Desarrollo de la Frontera Norte. Quito: I.G.M.

[12] Ministerio de Defensa Nacional. (2018). Política de la Defensa Nacional (Libro Blanco). Quito: Instituto Geográfico Militar (IGM).

[13] Moncayo Gallegos, P. R. (2016). Geopolítica: Espacio y Poder. Sangolquí-Ecuador: ESPE.

[14] Moncayo, P. (2018). La Política de Seguridad y Defensa. Revista de la Academia de Guerra del Ejército Ecuatoriano, 11 .

[15] Secretaría Nacional de Gestión de Riesgos. (2012). Manual del Comite de Gestión de Riesgos. GuayaquilEcuador: SNGR. Plan Nacional de Seguridad Integral. (2014).

[16] Política de Seguridad Integral. Seguridad Integral, plan y agendas 2014-2017. Quito, Pichincha, Ecuador. 